\title{
Identification of a new allele of the $D w$ gene causing brachytic dwarfing in peach
}

\author{
Celia M. Cantín ${ }^{1}$ Pere Arús ${ }^{2}$ and Iban Eduardo ${ }^{2^{*}}$ (1)
}

\begin{abstract}
Objective: Peach brachytic dwarfism determined by Dwarf gene $(D w)$ is an undesired trait segregating in some peach breeding programs. Recently, a single nucleotide polymorphism (SNP) mutation in the gibberellin insensitive dwarf 1 (GID1) peach gene causing brachytic dwarfism was described. In this research we wanted to validate this marker in an $\mathrm{F}_{2}$ population of the 'Nectavantop' peach cultivar ( $\mathrm{Nv}$ ) to include it as a marker assisted selection tool for peach breeding programs.

Results: The observed segregation of the trait was in agreement with that of a recessive gene, the individuals homozygous for the recessive allele ( $d w d w$ ) presenting the dwarf genotype. Dw was mapped to the distal part of linkage group 6 as previously described. The SNP marker based on the causal mutation previously described did not segregate in $\mathrm{NV}_{2}$ population. The sequence of the GID1C gene in Nv revealed a second SNP in its coding sequence which cosegregated with the dwarf phenotype. This SNP was predicted by the SNAP ${ }^{2}$ software to cause a major functional change and was validated in the dwarf peach cultivar 'Small sunning'. These results suggest the existence of at least two independent mutations of the Dw gene causing the peach brachytic dwarf phenotype.
\end{abstract}

Keywords: Tree architecture, Molecular marker, Prunus persica, Marker-assisted selection

\section{Introduction}

Until today different dwarf peach phenotypes have been described and different applications have been proposed for them, including the development of dwarf cultivars for intensive production, their use as ornamentals, and the use of genetically modified cultivars for the dwarfing genes to control fruit architecture [1]. The genetics of dwarf phenotypes has been studied and several major genes ( $D w, D w 2, D w 3)$ have been identified [2-6]. Homozygous individuals for either $d w$ or $d w 2$ display brachytic dwarfism (BD), presenting short internodes, thickened stems, reduced higher order branching, elongated leaves and normal fruit. Homozygous individuals for $d w 3$ are different from the previous ones and present narrow branches and willowy growth [7]. Dwarfing was also determined by a fourth gene $(N)$ where the $n n$ homozygote has short internodes, but $N n$ heterozygotes

\footnotetext{
*Correspondence: iban.eduardo@irta.cat

${ }^{2}$ IRTA, Centre de Recerca en Agrigenòmica CSIC-IRTA-UAB-UB, Campus

UAB, Cerdanyola del Vallès (Bellaterra), 08193 Barcelona, Spain

Full list of author information is available at the end of the article
}

generate semi-dwarf individuals $[8,9]$. Another dwarfing phenotype, recently described by $\mathrm{Lu}$ et al. [10], is the temperature-sensitive semi-dwarf (Tssd) locus that regulates internode length. The presence of the dominant Tssd allele determines short internode length at temperatures below $30^{\circ} \mathrm{C}$. Dw and Tssd have been mapped to the distal part of chromosome $6[6,11]$ and to the proximal part of chromosome 3 [10], respectively. Only $D w$ has been cloned [11], being the $d w$ allele generated by a nonsense mutation resulting in a non-functional product of the gibberellic acid (GA) receptor PpeGID1c gene [11]. PpeGID1c is annotated as Prupe.6G332800 in the peach genome v2.0 and as ppa018174 in v1.0. For the other dwarfing genes there is no information on their map positions or markers tightly linked to them.

BD individuals are often found to be segregating in peach breeding programs and they are usually discarded. Molecular markers such as the gid1c SNP described by Hollender et al. [11], can be used as tools for early identification and removal of dwarf plants in peach breeding programs or to avoid crosses between carriers of the $d w$ 
allele. Several molecular markers for other traits such as fruit shape [12], fruit acidity [13] and the slow ripening phenotype [14], among others [15], are already being used routinely for marker-assisted selection (MAS) in peach [16]. In this work, we describe the identification of a new allele from the $D w$ gene producing dwarf individuals found in 'Nectavantop' and 'Small sunning' cultivars.

\section{Main text \\ Methods \\ Plant material and DNA extraction}

A dwarf segregating population of 77 individuals obtained from the open pollination (OP) of 'Nectavantop' $(\mathrm{Nv})$ cultivar was used for this study. Trees were planted on their own roots in 2013 in the plots at the IRTA Experimental Station at Gimenells (Lleida, Spain). Trees were visually classified as normal or dwarf during 2 consecutive years (2014 and 2015), that corresponded to the first and second year after planting. Concurrently, one tree of dwarf cultivars 'Bonanza' (Bo) and 'Small sunning' (Ss) were grown in $50 \mathrm{~L}$ pots in the IRTA greenhouse at Torre Marimon (Caldes de Montbui, Spain). DNA from the 77 genotypes of $\mathrm{Nv} \otimes$ and $\mathrm{Nv}$, Bo and Ss was extracted from young leaf tissue using the Doyle and Doyle [17] protocol adapted to 96 well plates.

\section{Genotyping}

For simple sequence repeat (SSR) genotyping, polymerase chain reactions (PCR) reactions were carried out in a PE9700 Thermal Cycler (PE/Applied Biosystems, Foster City, California, USA) in a volume of $10 \mu \mathrm{l}$, containing $20 \mathrm{ng}$ of peach genomic DNA, $1 \times$ NH4-based Reaction Buffer, $1.5 \mathrm{mM} \mathrm{MgCl} 2,0.5 \mathrm{mM}$ dNTPs, $0.25 \mu \mathrm{M}$ of each primer and $1 \mathrm{U}$ of BIOTAQ (Bioline). Forward primers were labelled with a fluorochrome (FAM, VIC, NED or PET). PCR amplifications were carried under the following conditions: $1 \mathrm{~min}$ at $95{ }^{\circ} \mathrm{C}, 30$ cycles of $15 \mathrm{~s}$ at $95^{\circ} \mathrm{C}, 15 \mathrm{~s}$ at the appropriate annealing temperature, and $30 \mathrm{~s}$ at $72{ }^{\circ} \mathrm{C}$, followed by a $5 \mathrm{~min}$ extension at $72{ }^{\circ} \mathrm{C}$. Products were analyzed by capillary electrophoresis using the ABI/ Prism 3130xl (PE/Applied Biosystems) sequencer as in Aranzana et al. [18]. CPP SSRs were genotyped using the multiplex-ready PCR as described in Donoso et al. [19]. A SNP located within the candidate gene GID1c and called gid1c was described by Hollender et al. [11] as the causal mutation from the BD phenotype. Primers to amplify a DNA fragment containing gid1c were designed (Table 1) to genotype it by Sanger sequencing. PCR conditions for fragment amplification were the same than those of the SSRs, but using 1 min of extension. PCR fragments were visualized in ethidium bromide agarose gels under UV light for amplification
Table 1 Primers of the five new SSRs used to map the dwarf trait and the two primers for SNP genotyping

\begin{tabular}{lll}
\hline Primer name & Primer sequence & Genomic position \\
\hline CPP24554-F & TGAGGGAAGTTTGGTTGCTC & $6: 28182155$ \\
CPP24554-R & AATTGAGATGAATGGGGCGC & $6: 28182388$ \\
CPP24650-F & GGCACGTGAGAGGGATATGA & $6: 28892277$ \\
CPP24650-R & AACTTAAGTCAGCGGCAGGAT & $6: 28892516$ \\
CPP24654-F & GGGGTAAATAAGACTTTTGACAACT & $6: 28897444$ \\
CPP24654-R & AGTCGGTCTAAGGTGTGAAAACA & $6: 28897685$ \\
CPP24664-F & ATTAAACCACAGACGCACGG & $6: 28996880$ \\
CPP24664-R & TGACCATGTGCGTATCATTTGT & $6: 28997069$ \\
CPP24681-F & TTCCCTGCTTGACACGTGTA & $6: 29123267$ \\
CPP24681-R & ACACTCACTCTGTCTTCCGGT & $6: 29123396$ \\
Ppa018174-F & AACTGGCCTGCTTACTCGAA & $6: 28967552$ \\
ppa018174-R & GCCAGTCCTGAACAAGATCC & $6: 28966891$ \\
\hline
\end{tabular}

Genomic positions are according to the Prunus genome v2.0

pattern verification, later on they were sequenced in the capillary sequencing service from CRAG (http://www. cragenomica.es/core-facilities/capillary-sequencing) using standard protocols.

\section{Linkage mapping}

$\mathrm{Nv} \otimes$ was first screened with four SSR markers (UDP98412, МА014a, СРРСТ030, СРРСТ021) known to be located at the distal end of linkage group 6 (G6) where the peach $D w$ gene had been previously mapped $[6,11]$. Five additional SSRs were developed at this region using the peach genome sequence v2.0 (http://www.rosaceae. org), and the set of SSRs described in http://services.appli edgenomics.org/projects/drupomics/gbrowse/. The new SSRs were noted as CPP followed by the number assigned to this SSR in the IGA (Istituto di Genomica Applicata) annotation of the peach genome v1.0 (Table 1). Six out of the nine SSRs screened in Nv were heterozygous and were genotyped in the progeny. The other three SSRs (MA014a, CPPCT021 and CPP24554) were homozygous in Nv and could not be used for mapping. Eight individuals were found to contain alleles different from those of $\mathrm{Nv}$ in at least one marker indicating that they came from cross pollination and were discarded from the dataset. The remaining 69 individuals were considered as true $\mathrm{F}_{2}$ individuals and used for map construction.

A linkage map was constructed using JoinMap v.4.1 [20] software. Groups were established with a LOD $\geq 3.0$ and the map was calculated with the Kosambi distance function. Linkage group nomenclature follows the Prunus reference map $(\mathrm{T} \times \mathrm{E})$ [21]. MapChart 2.1 software [22] was used to draw the map. To predict the effects of a new sequence variant identified in this research on 
the function of the PpeGID1c gene product we used the SNAP $^{2}$ software program [23].

\section{Results}

\section{Genetic mapping of Dw}

Dwarf trees from Nv population were much smaller and with shorter internodes than normal trees (Fig. 1). The description of the dwarf trees corresponded very well with that of Hollender et al. [11], and differences between normal and dwarf trees were already evident from the beginning of seedling development. Twentytwo out of the $69 \mathrm{~F}_{2}$ individuals were dwarf, representing a 47:22 segregation, which fits with a 3:1 segregation $\left(\chi^{2}=1.74 ;\right.$ n.s. $)$. This suggests that the BD trait was controlled by a single gene $(D w)$ with $d w$ as a recessive allele, as previously described $[6,11] . D w$ was codified according to that and was included with the other six SSRs in the mapping dataset. A single linkage group (LG), corresponding to Prunus LG6, was identified (Fig. 1), where $D w$ was cosegregating with markers CРPCT030, CPP24650, CPP24654, CPP24664 and CPP24681, spanning a genomic region of approximately $400 \mathrm{Mb}$ according to the Prunus genome v2.0, and UDP98-412 was 12.4 cM apart.

\section{SNP identification in the GID1c candidate gene}

The chromosomal region delimited by the markers cosegregating with $D w$, co-locates with that of the candidate gene GID1c reported by Hollender et al. [11]. These authors demonstrated that the $A / A$ genotype from

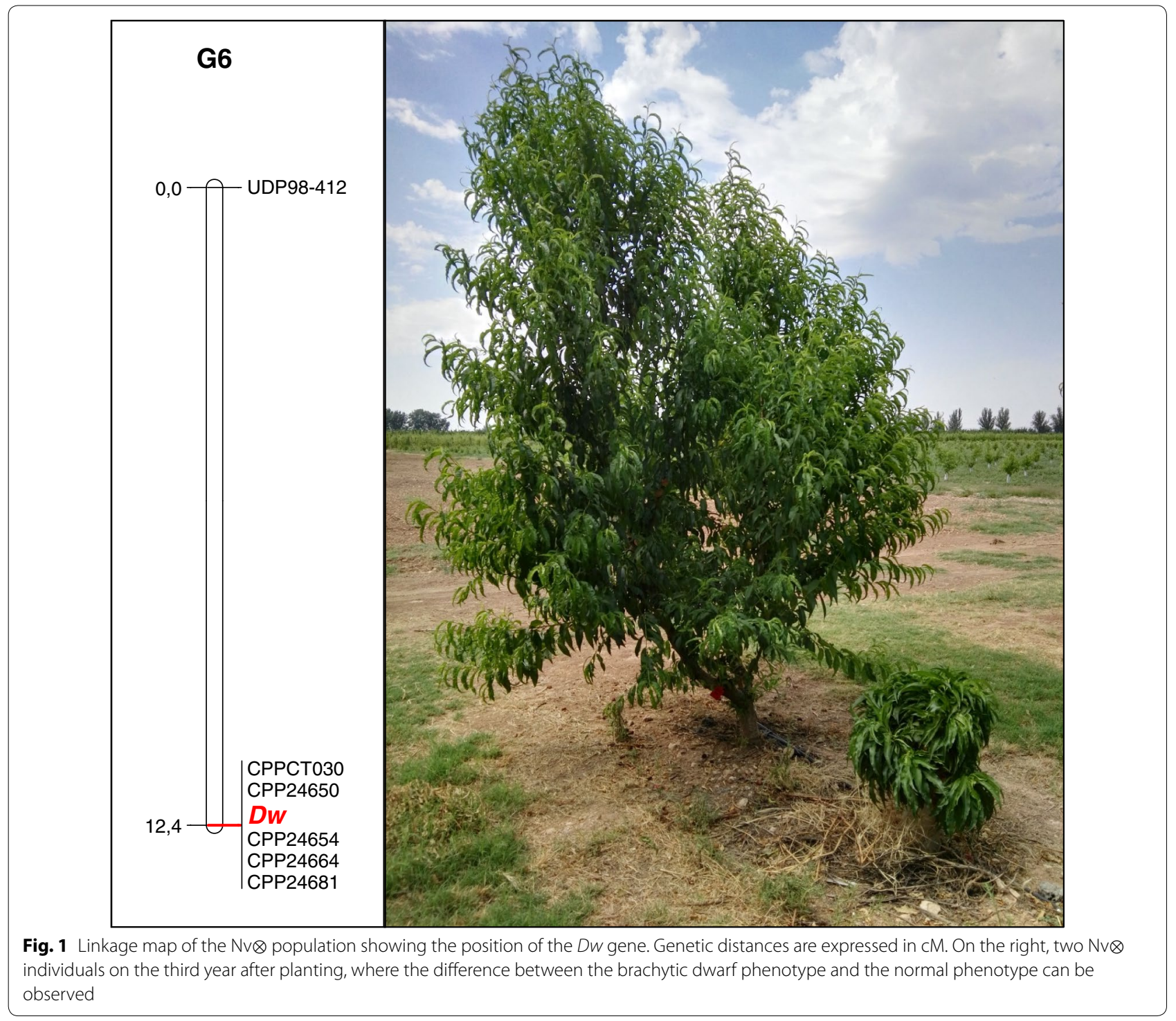


SNP-W162* was responsible for the BD trait [11]. This SNP is physically located between markers CPP24654 and CPP24664, suggesting that it could be also responsible for the phenotypic variability observed in $\mathrm{NvF}_{2}$ population. To validate that option, a DNA fragment of $662 \mathrm{bp}$ around the SNP-W162* was amplified and sequenced in 'Nectavantop', 'Bonanza,' 'Small sunning' and two normal and two dwarf $\mathrm{Nv} \mathrm{F}_{2}$ individuals. These sequences contained two SNPs, one corresponding to the SNP-W162* and another one 87 bp further, which we named SNP$\mathrm{S} 178 \mathrm{~F}$. The only individual presenting the dwarf allele $(A / A)$ in the SNP-W162*, was 'Bonanza'. The new SNP, SNP-S178F, was found to have the $T / T$ genotype in the two dwarf individuals from the $\mathrm{Nv} \mathrm{F}_{2}$ population and in 'Small sunning, was heterozygous $(C / T)$ in 'Nectavantop' and the normal size $\mathrm{F}_{2}$ individuals, and was homozygous $\mathrm{C} / \mathrm{C}$ in 'Bonanza' (Fig. 2).

\section{SNP effect prediction}

The new SNP-S178F results in an amino acid substitution of a serine (TCT) for a phenylalanine (TTT) in the gibberellic acid receptor protein encoded by the GID1c gene. To predict the possible effect of this mutation in the product of this gene, its sequence was analyzed with SNAP $^{2}$ software. The SNP-S178F is located in a region of 12 amino acids where mutations can have a high effect on the protein functionality. In our case, the substitution of a Serine by a Phenylalanine presents a high score only exceeded by three other amino acidic changes (Additional file 1), suggesting that the effect of this mutation is sufficiently important to disrupt the functionality of the transcribed protein with phenotypic effects that are indistinguishable from the allele detected by the
SNP-W162*, originally found in the Japanese cultivar 'Juseito', which produces a stop codon [11].

\section{Discussion}

Our results indicate that the $\mathrm{BD}$ phenotype segregating in the $\mathrm{Nv} \mathrm{F}_{2}$ population, although mapping in the same position at the distal part of G6, is not caused by the SNP described by Hollender et al. [11], but by a different allele. As it occurs for other peach genes that have been characterized at the molecular level in peach, such as the white vs. yellow flesh color [24], various alleles of different origin may cause similar recessive phenotypes. One of the consequences of this is that selection for markers based on the causal allele may be useful for only one transect of the variability of the species and are useless for the other. Knowledge of the pedigree of the individuals sampled is then a requirement for the adequate choice of markers. This shows also that even in a species with a low level of variability like peach [25], multiallelic series may be common for genes with phenotypic effects. While in the case of the yellow vs. white gene may be attributed to the amplification of variability caused by human selection for characters related with the edible part of the plant in crop species, it appears not to be the case for the dwarf gene, where the homozygous recessive dwarf individuals are usually rejected.

\section{Limitations}

The main limitations of our results are the low resolution of our mapping population, probably because of the reduced number of individuals used and the low number of cultivars where both SNPs markers, W162* and S178F, could be validated.

\begin{tabular}{|c|c|c|}
\hline Plant & Phenotyp & W162* \\
\hline Nectavantop & $\mathbf{N}$ & 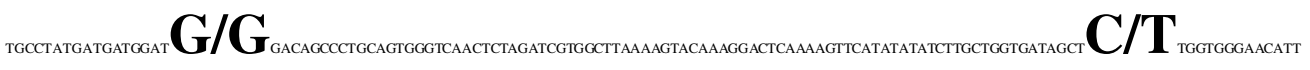 \\
\hline Bonanza & D & 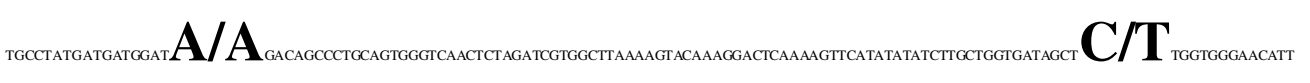 \\
\hline Small sunning & D & 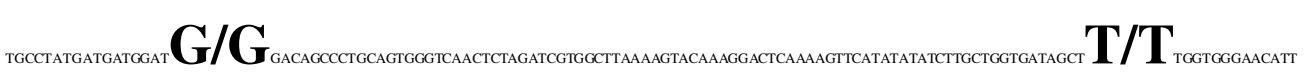 \\
\hline Dwarf-1 & D & 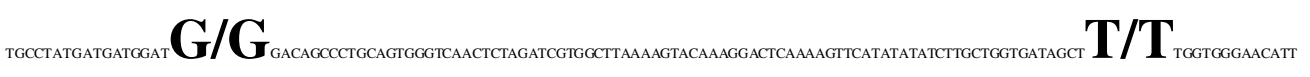 \\
\hline Dwarf-2 & D & 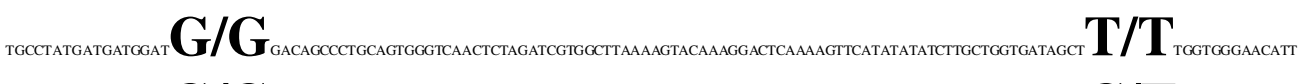 \\
\hline Normal-1 & $\mathbf{N}$ & 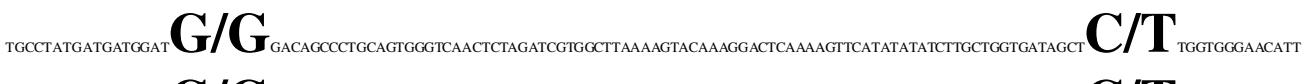 \\
\hline Normal-2 & $\mathbf{N}$ & 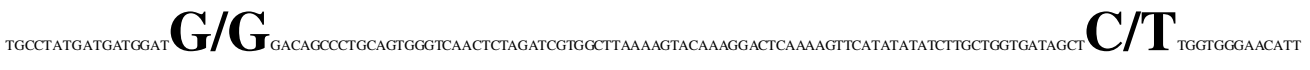 \\
\hline Lovell & $\mathbf{N}$ & 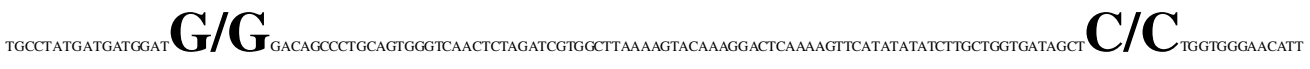 \\
\hline
\end{tabular}

Fig. 2 Sequence fragment from GID1C (Prupe.6G332800) gene containing both SNPs, w162* and the new S178F SNP described in this work. Genotypes of the different cultivars for both SNPs are shown. Phenotypes are indicated as normal (N) or dwarf (D) 


\section{Additional file}

Additional file 1. Functional effects in the protein encoded by the GIDIC (Prupe.6G332800) sequence predicted by the SNAP2 software. (A) Global view of effects in the full protein sequence. The Serine affected by the gid1c2 SNP is marked with an arrow. (B) Scores of the different possible mutations in the Serine affected by the gid 1 c2 SNP. The specific change of a Serine for a Phenylalanine is marked with an arrow.

\section{Abbreviations}

BD: brachytic dwarfism; Bo: Bonanza; DNA: deoxyribonucleic acid; Dw: dwarf GA: gibberellic acid; GID1: gibberellin insensitive dwarf 1; LG: linkage group; MAS: marker assisted introgression; Nv: nectavantop; PCR: polymerase chain reaction; SNP: single nucleotide polymorphism; Ss: Small sunning; SSR: simple sequence repeat; Tssd: temperature-sensitive semi-dwarf.

\section{Authors' contributions}

CC provided plant material, phenotypic data and helped to draft the manuscript. PA participated in the design of the study and helped to draft the manuscript. IE performed the data analysis, conceived the study and participated in the design and coordination, and drafted the manuscript. All authors read and approved the manuscript.

\section{Author details}

${ }^{1}$ IRTA, FruitCentre, Parc Científic i Tecnològic Agroalimentari de Lleida (PCiTAL), Edifici Fruitcentre, Parc de Gardeny, 25003 Lleida, Spain. ${ }^{2}$ IRTA, Centre de Recerca en Agrigenòmica CSIC-IRTA-UAB-UB, Campus UAB, Cerdanyola del Vallès (Bellaterra), 08193 Barcelona, Spain.

\section{Acknowledgements}

Not applicable.

\section{Competing interests}

The authors declare that they have no competing interests.

\section{Availability of data and materials}

The datasets generated and/or analysed during the current study are available from the corresponding author on reasonable request.

\section{Consent for publication}

Not applicable.

\section{Ethics approval and consent to participate}

Not applicable.

\section{Funding}

We acknowledge financial support from the Spanish Ministry of Economy and Competitiveness, through the "Severo Ochoa Programme for Centres of Excellence in R\&D"2016-2019 (SEV-2015-0533)" and project AGL2012-40228, and from the CERCA Programme from the Generalitat de Catalunya.

\section{Publisher's Note}

Springer Nature remains neutral with regard to jurisdictional claims in published maps and institutional affiliations.

Received: 29 March 2018 Accepted: 5 June 2018 Published online: 14 June 2018

\section{References}

1. Scorza R. Theory and practice of genetically manipulating peach tree architecture. NY Fruit Q. 2005;13(4):27-31.

2. Lammerts W. The breeding of ornamental edible peaches for mild climates. I. Inheritance of tree and flower characters. Am J Bot. 1945;32:53-61.

3. Scorza R. Characterization of four distinct peach tree growth types. J Am Soc Hortic Sci. 1984;109:455-7.
4. Hansche PE. Two genes that induce brachytic dwarfism in peach. HortScience. 1998;23:604-6.

5. Monet R. Peach genetics: past present and future. Acta Hortic. 1989;254:49-57.

6. Yamamoto T, Yamaguchi M, Hayashi T. An integrated genetic linkage map of peach by SSR, STS, AFLP and RAPD. J Jpn Soc Hortic Sci. 2005;74(3):204-13.

7. Chaparro JX, Werner DJ, O'Malley D, Sederoff RR. Targeted mapping and linkage analysis of morphological isozyme, and RAPD markers in peach. Theor Appl Genet. 1994;87:805-15.

8. Monet R, Salesses G. Un nouveau mutant de nanisme chez le pecher. Annales de l'Amélioration des Plantes. 1975;25:353-9.

9. Gradziel TM, Beres W. Semidwarf growth habit in clingstone peach with desirable tree and fruit qualities. HortScience. 1993;28:1045-7.

10. Lu Z, Niu L, Chagné D, Cui G, Pan L, Foster T, Zhang R, Zeng W, Wang Z. Fine mapping of the temperature-sensitive semi-dwarf (Tssd) locus regulating the internode length in peach (Prunus persica). Mol Breed. 2016;36:20.

11. Hollender C, Hadiarto T, Srinivasan C, Scorza R, Dardick C. A brachytic dwarfism trait $(d w)$ in peach trees is caused by a nonsense mutation within the gibberellic acid receptor PpeGID1c. New Phytol. 2016;210(1):227-39

12. Picañol R, Eduardo I, Aranzana M, Howad W, Batlle I, Iglesias I, Alonso J, Arús P. Combining linkage and association mapping to search for markers linked to the flat fruit character in peach. Euphytica. 2013;190(2):279-88.

13. Eduardo I, López-Girona E, Batlle I, Reig G, Iglesias I, Howad W, Arús P, Aranzana M. Development of diagnostic markers for selection of the subacid trait in peach. Tree Genet Genomes. 2014;10(6):1695-709.

14. Eduardo I, Picañol R, Rojas E, Batlle I, Howad W, Aranzana M, Arús P. Mapping of a major gene for the slow ripening character in peach: co-location with the maturity date gene and development of a candidate genebased diagnostic marker for its selection. Euphytica. 2015;205(2):627-36.

15. Lambert P, Campoy JA, Pacheco I, Mauroux JB, Da Silva Linge C, Micheletti D, Bassi D, Rossini L, Dirlewanger E, Pascal T, Troggio M, Aranzana MJ, Patocchi A, Arús P. Identifying SNP markers tightly associated with six major genes in peach [Prunus persica (L.) Batsch] using a high-density SNP array with an objective of marker-assisted selection (MAS). Tree Genet Genomes. 2016;12:121.

16. Eduardo I, Cantín CM, Batlle I, Arús P. Integración de los marcadores moleculares en un programa de mejora de variedades de melocotonero. Fruticultura. 2015;44:7-17

17. Doyle JJ, Doyle JL. Isolation of plant DNA from fresh tissue. Focus. 1990;12:13-5.

18. Aranzana MJ, Carbó J, Arús P. Microsatellite variability in peach [Prunus persica (L.) Batsch]: cultivar identification, marker mutation, pedigree inferences and population structure. Theor Appl Genet. 2003;106:1341-52.

19. Donoso JM, Picañol R, Eduardo I, Batlle I, Howad W, Aranzana MJ, Arús P. High-density mapping suggests a cytoplasmic male sterility system with two restorer factors in almond $x$ peach progenies. Hortic Res. 2015;2:15016.

20. Van Ooijen JW. Multipoint maximum likelihood mapping in a full-sib family of an outbreeding species. Genet Res. 2011;93(5):343-9.

21. Dirlewanger E, Graziano E, Joobeur T, Garriga-Calderé F, Cosson P, Howad W, Arús P. Comparative mapping and marker-assisted selection in Rosaceae fruit crops. Proc Natl Acad Sci USA. 2004;101:9891-6.

22. Voorrips RE. MapChart: Software for the graphical presentation of linkage maps and QTLs. J Hered. 2002;93(1):77-8.

23. Hecht M, Bromberg Y, Rost B. Better prediction of functional effects for sequence variant. BMC Genomics. 2015;16(Suppl 8):S1.

24. Falchi R, Vendramin E, Zanon L, Scalabrin S, Cipriani G, Verde I, Vizzotto G, Morgante M. Three distinct mutational mechanisms acting on a single gene underpin the origin of yellow flesh in peach. Plant J. 2013;76:175-87.

25. Micheletti D, Dettori MT, Micali S, Aramini V, Pacheco I, da Silva C, Foschi S, Banchi E, Barreneche T, Quilot-Turion B, Lambert P, Pascal T, Iglesias I, Carbó J, Wang LR, Ma RJ, Li XW, Gao ZS, Nazzicari N, Troggio M, Bassi B, Rossini L, Verde I, Laurens F, Arús P, Aranzana MJ. Whole-genome analysis of diversity and SNP-major gene association in peach germplasm. PLoS ONE. 2015;10(9):e0136803. 